\title{
Offline Photovoltaic Maximum Power Point Tracking
}

\author{
Fyali Jibji-Bukar ${ }^{1}$, and Olimpo Anaya-Lara ${ }^{1}$ \\ ${ }^{1}$ University of Strathclyde, Department of Electrical and Electronics Engineering, 16 Richmond Street, G1 1XQ, Glasgow, United \\ Kingdom
}

\begin{abstract}
As more renewable energy sources are connected to the electrical grid, it has become important that these sources participate in providing system support. It has become needful for grid-connected solar photovoltaics to participate in support functions like frequency support. However, photovoltaic systems need to implement a maximum power tracking algorithm to operate at maximum power and a method for de-loading photovoltaic systems is necessary for participation in frequency support. Some conventional maximum power tracking techniques are implemented in real time and will not adjust their output fast enough to provide system support while other may respond fast but are not very efficient in tracking the maximum power point of a photovoltaic system. This paper presents an offline method to estimate the maximum power voltage and current based on the characteristics of the photovoltaics module available in the datasheet and using the estimated values to operate the photovoltaics at maximum power. The performance of this technique is compared to the conventional technique. This paper also describes how the photovoltaic system can be de-loaded.
\end{abstract}

\section{Introduction}

Power in electrical systems is increasingly supplied from diverse generation sources. As sources such as photovoltaics gain a larger share of power generation and replace conventional generators, the inertia of power systems will be reduced. The could lead to a high rate of change of frequency when there is a difference in generation and demand [1]. This problem is exacerbated in island systems where there are very few generators and high renewable energy penetration because they have reduced inertia and variability in power generation which could lead to more frequency deviation events [2]. As a result of this, it has become important for different kinds of generation sources to participate in frequency support if more renewable generation is to be added to electrical grids.

Wind turbines have been demonstrated to contribute to frequency support by providing inertia support and providing primary frequency support similar to the support obtainable from conventional power plants in [3] and [4]. Energy storage systems have also been shown to provide frequency support. In [5], flywheel energy storage system is shown to provide frequency support. Battery storage systems can also be used to provide frequency support as shown in [6]. This is because they are fast-acting and can increase active power supply in the time-scale of inertia response.

Like battery storage systems, PV systems can support grid frequency with the appropriate control and operation method. However, PV systems require a maximum power point tracking method. Common methods used for operating PV at maximum power include perturb and observe, incremental conductance and fractional open-circuit voltage [7]. These methods are not suitable for systems required to provide frequency support because they either require significant computation which makes them slower or are fast but lead to significant power losses.

Various methods for estimating PV power have been proposed in [8] and [9]. [8] uses artificial neural network but this will require historical information on the performance of the PV system and the method used in [9] will require some real-time calculation to estimate maximum power. This paper proposes a method to operate the PV systems at maximum power by obtaining the maximum power voltage from the PV currentvoltage (I-V) curve for the entire operating range of the $\mathrm{PV}$ module using the characteristics of the PV module from the PV datasheet.

Section 2 describes the effect of temperature and irradiance on the open-circuit voltage $\left(V_{\mathrm{OC}}\right)$ and shortcircuit $\left(I_{\mathrm{SC}}\right)$ and how $V_{\mathrm{OC}}$ and $I_{\mathrm{SC}}$ can be estimated for any combination of temperature and irradiance. Section 3 describes how the maximum power voltage and current can be calculated from the I-V curve and how the PV system can be operated at the desired de-loading level. Section 4 presents the operation of the proposed method and compares the result with operation using incremental conductance.

\section{Estimating Voc and Isc}

\subsection{Effect of Changing Irradiance}


The $I_{\mathrm{SC}}$ current varies directly with the irradiance up to very high levels of irradiance [10]. This is because the generated photocurrent is a direct result of the amount of available sunlight. This implies that for any given temperature, the $I_{\mathrm{SC}}$ can be readily determined. The $I_{\mathrm{SC}}$ current at standard testing condition (STC) is available in the datasheet. The $V_{\mathrm{OC}}$ is also affected - to a lesser extent -by changing irradiance. The $V_{\mathrm{OC}}$ changes logarithmically to the irradiance. Figure 1 shows the I-V at different irradiances and constant temperature.

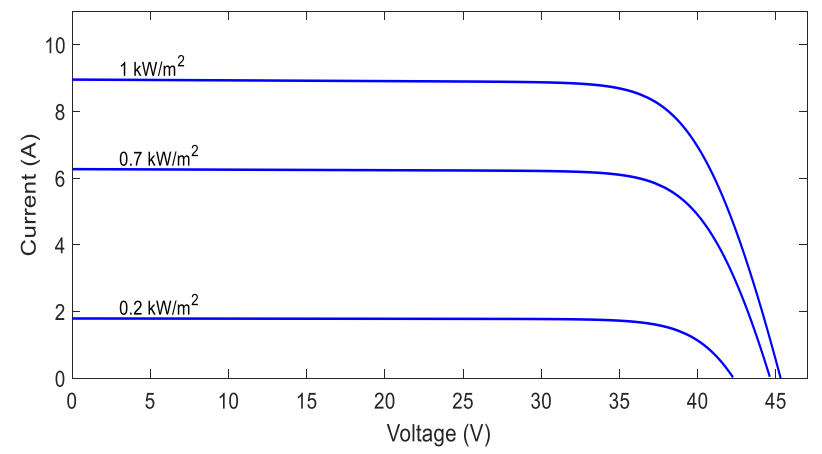

Fig. 1.Effect of Changing Irradiance on $V_{\mathrm{OC}}$ and $I_{\mathrm{SC}}$

\subsection{Effect of changing temperature}

A change in temperature results in a change in both the $V_{\mathrm{OC}}$ and $I_{\mathrm{SC}}$. As temperature increases, the $I_{\mathrm{SC}}$ increases while the $V_{\mathrm{OC}}$ reduces. This results in

an overall loss of efficiency with increasing temperature. This is because the increase in temperature leads to an increase in the bandgap of the semiconductor which leads to an increase in the $I_{\mathrm{SC}}[11]$. $V_{\mathrm{OC}}$ reduces with an increase in temperature because of the increase in the dark current density [11].

The effect of temperature on $V_{\mathrm{OC}}$ and $I_{\mathrm{SC}}$ is defined by the temperature coefficient of the PV module and is provided by the manufacturer in the module datasheet. Figure 2 shows the effect of changing temperature on the $\mathrm{I}-\mathrm{V}$ curve of the PV module.

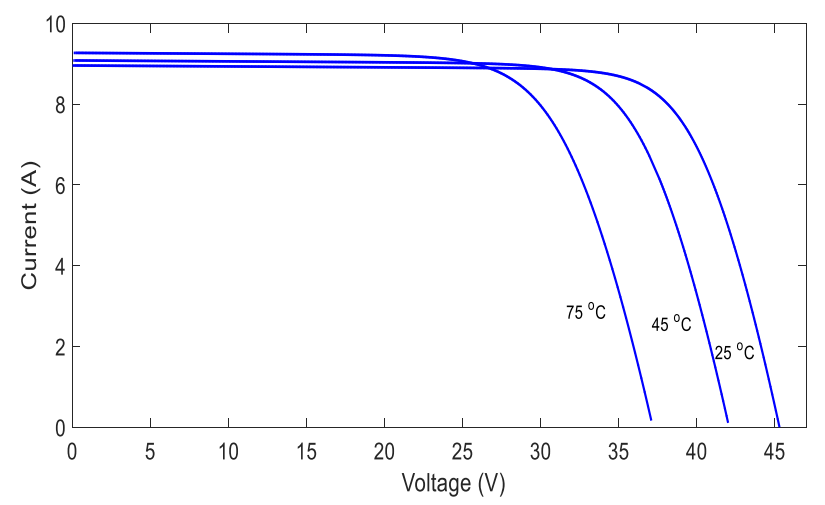

Fig. 2.Effect of Changing Temperature on $V_{\mathrm{OC}}$ and $\mathrm{ISC}_{\mathrm{SC}}$

\subsection{Effect of series and shunt resistances}

The series and shunt resistances of the PV module/cell make up the parasitic resistances. They reduce the efficiency of solar cells. The series resistance is as a result of the resistance of the electrical contact of the cell [12]. The series resistance does not affect the $V_{\mathrm{OC}}$ except at high values. The effect of the series resistance can be discounted in estimating $V_{\mathrm{OC}}$.

The shunt or parallel resistance is as a result of leakage current from the side of the cell which leads to loss of power and should be as high as possible to reduce losses [12]. The shunt resistance has no significant effect in measuring $V_{\mathrm{OC}}$ and $I_{\mathrm{SC}}$. The parasitic resistances result in a shift in the maximum power point and must be considered in obtaining the I-V curve.

Figure 3 below shows the I-V curve of a Trina Solar TSM310PD14 cell with the series and shunt (parasitic) resistances and without the series and shunt resistances. The $V_{\mathrm{OC}}$ and $I_{\mathrm{SC}}$ changed very little but there is a significant shift in the maximum power point. The maximum power voltage dropped from $0.5536 \mathrm{~V}$ without the parasitic resistances to $0.5033 \mathrm{~V}$ with the parasitic resistances while the maximum power current dropped from $8.4533 \mathrm{~A}$ to $8.3256 \mathrm{~A}$. This presence of the parasitic resistances resulted in a maximum power loss of $0.4895 \mathrm{~W}$ which is about $10 \%$ of the power without the parasitic resistances. The shunt and series resistances are not given in the module datasheet but can be calculated using the method described in [13].

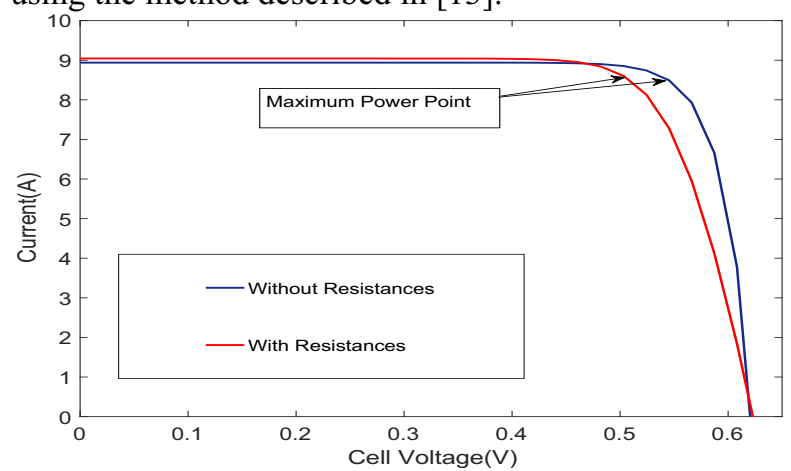

Fig.3. I-V curve of TSM310PD14 at STC with and without Parasitic Resistances

\section{Obtaining the I-V curves}

The first step in obtaining the I-V curves is to determine the $I_{\mathrm{SC}}$ and $V_{\mathrm{OC}}$ for all values of temperature and irradiance. This is done by extrapolation of the I-V curve at standard testing condition (STC) using the effect of changing irradiance and temperature on $I_{\mathrm{SC}}$ and $V_{\mathrm{OC}}$.

Two tables are generated for the $V_{\mathrm{OC}}$ and $I_{\mathrm{SC}}$. The range of irradiance considered is from $0-1700 \mathrm{w} / \mathrm{m}^{2}$ in intervals of $50 \mathrm{w} / \mathrm{m}^{2}$ while the range of temperature considered is from $-40^{\circ} \mathrm{C}$ to $85^{\circ} \mathrm{C}$ in intervals of one. The PV module used is the Trina Solar TSM-310PD14.

\subsection{Calculating $V_{\mathrm{oc}}$}

The Effect of temperature on $V_{\mathrm{OC}}$ is given by the temperature coefficient which is given in the module datasheet. At a given the irradiance, $V_{\mathrm{OC}}$ is given by equation 1 .

$$
V_{\mathrm{OC}}(t)=V_{\mathrm{OC}}(S T C)+\alpha(t-25)
$$


Where $\alpha$ is the temperature coefficient of the opencircuit voltage and $\mathrm{t}$ is temperature. To determine the $V_{\mathrm{OC}}$ for any irradiance (I) at a given temperature, equation 2 is used.

$$
V_{O C}=m k_{B} T \ln \left(\frac{I_{S C}}{J_{0}}+1\right)
$$

Where $\mathrm{m}$ is the diode ideality factor, $k_{\mathrm{B}}$ is the Boltzmann constant, $J_{0}$ is the diode saturation current and $T$ is the temperature in Kelvin. To obtain the $V_{\mathrm{OC}}$ voltage for any combination of irradiance and temperature, equation 1 and 2 are combined resulting in equation 3. Equation 3 gives the $V_{\mathrm{OC}}$ for any temperature and irradiance combination.

$$
V_{O C}(I, T)=m k B T \ln \left(\frac{I_{S C}(I, T)}{J_{0}}+1\right)+\alpha(T-25)
$$

\subsection{Calculating $/ \mathrm{sc}$}

The $I_{\mathrm{SC}}$ should be calculated first because it is needed in equation 3 to calculate the $V_{\mathrm{OC}}$. $I_{\mathrm{SC}}$ varies linearly with the irradiance for any given temperature. The $I_{\mathrm{SC}}$ for a given irradiance at any temperature is given in equation 4.

$$
I_{\mathrm{SC}}(t)=I_{\mathrm{SC}}(S T C)+\alpha(t-25)
$$

Where $\alpha$ is the temperature coefficient of the shortcircuit current. To obtain the $I_{\mathrm{SC}}$ for any combination of temperature and irradiance, the $I_{\mathrm{SC}}$ at STC have to first be adjusted for the irradiance and then adjusted for the difference in temperature from $25^{\circ} \mathrm{C}$. Equation 5 can be used to calculate the short-circuit current for any temperature and irradiance.

$$
I_{S C}(I, T)=\frac{I}{1000} \times I_{S C}(S T C)+\alpha(T-25)
$$

\subsection{Calculating maximum power voltage/current}

To determine the maximum power point at any irradiance and temperature, the I-V and P-V curves need to be obtained. PV cell can be modelled as a current source connected in parallel to a diode and the shunt resistance $\left(\mathrm{R}_{\mathrm{SH}}\right)$ and in series to the series resistance $\left(R_{S}\right)$. The five parameter model of a PV cell is given in figure 4 .

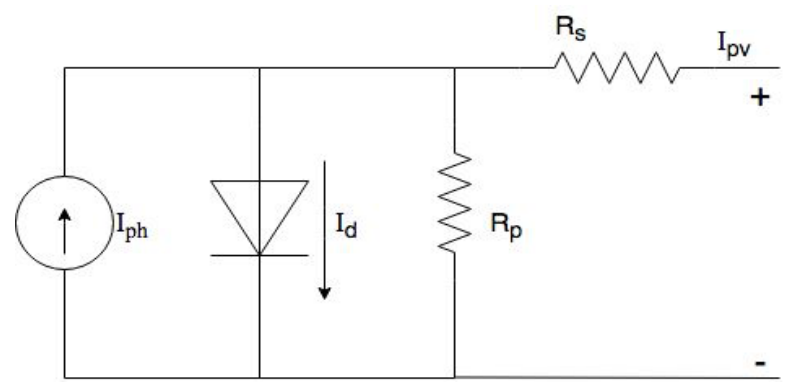

Fig. 4. Five parameter model of a solar cell
The I-V curve can be obtained by solving for the current in the terminal of the module. The current from $\mathrm{PV}$ module is given by equation 6 .

$$
i=I_{S C}-J_{0}\left(e^{q\left(V+J R_{S}\right) / k T}-1\right)-\frac{V-J R_{S}}{R_{S H}}
$$

Where $i$ is the current across the terminals of the $\mathrm{PV}, \mathrm{R}_{\mathrm{SH}}$ is the shunt/parallel resistance, $R_{S}$ is the series resistance, $V$ is the voltage and $\mathrm{q}$ is the electric charge.

The I-V curve can be obtained by solving the equation 6 . The voltage should be taken in small steps from 0 to $V_{\mathrm{OC}}$ and the current computed to obtain the I-V curve. The step should be as small as possible as the maximum power point is usually around the end of the curve. This will increase the accuracy of the curve. However, equation 6 is an implicit equation and have to be solved numerically. For every voltage from $0-V_{\mathrm{OC}}$, the value of current which satisfies the equation is determined numerically. This was done using the fzero function in Matlab. Figure 5 shows the I-V curve at different points using the described method.

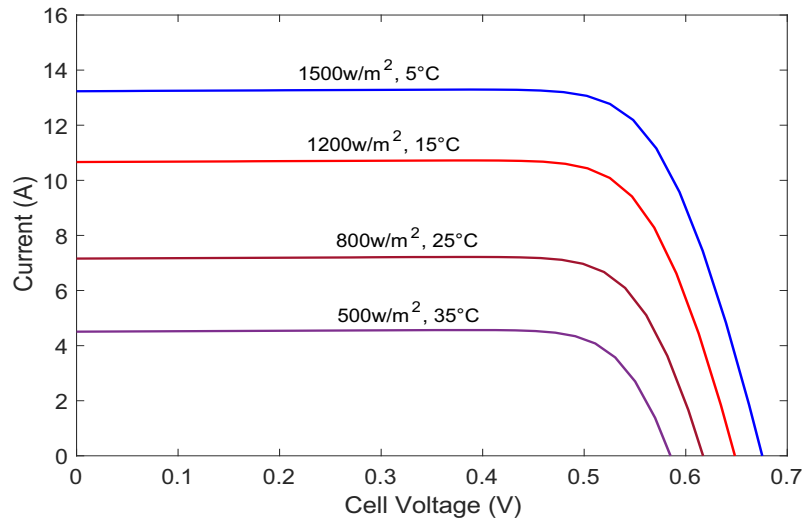

Fig. 5.Calculated IV curves

The maximum power point can be determined by plotting the graph of voltage against power. It is the highest point in the PV graph. Table 1 shows the maximum power voltage of one module of Trina Solar TSM 310 PD14 at different temperature and irradiance using the described process.

Table 1: Calculated maximum power voltages

\begin{tabular}{|l|l|l|l|l|}
\hline Irradiance & $-20^{\circ} \mathrm{C}$ & $25^{\circ} \mathrm{C}$ & $45^{\circ} \mathrm{C}$ & $65^{\circ} \mathrm{C}$ \\
\hline 500 & 42.12 & 36.4 & 33.72 & 31.13 \\
\hline 1000 & 42.04 & 36.8 & 33.4 & 30.3 \\
\hline 1500 & 41.41 & 36.2 & 33.15 & 30.61 \\
\hline 1700 & 41.63 & 35.4 & 32.25 & 29.78 \\
\hline
\end{tabular}

\section{Operating PV system at maximum power}

To test the proposed method, a PV system was modelled in Simulink. The maximum power points at different operating conditions are calculated and stored in a lookup table. Because of the number of possible combinations of temperature and irradiance, it is 
important that only a manageable number of power points are calculated for. For any irradiance and temperature value not stored in the lookup table, the closest approximation should be used.

For any combination of temperature and irradiance, the lookup table will give the maximum power voltage as the reference voltage. The reference voltage will then be used to obtain the duty cycle which will be the input of the DC-DC converter. The operation of the system is shown in figure 6 below.

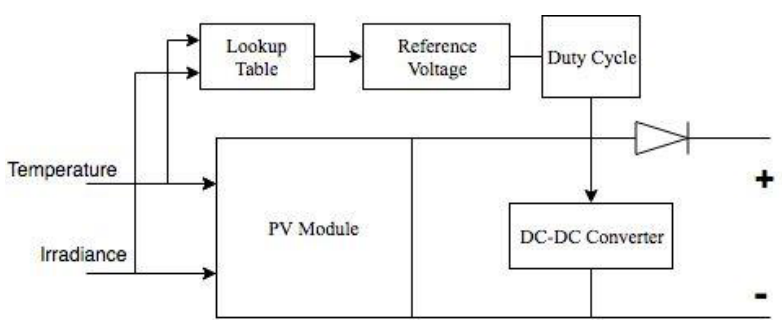

Fig. 6.Offline MPPT Implementation
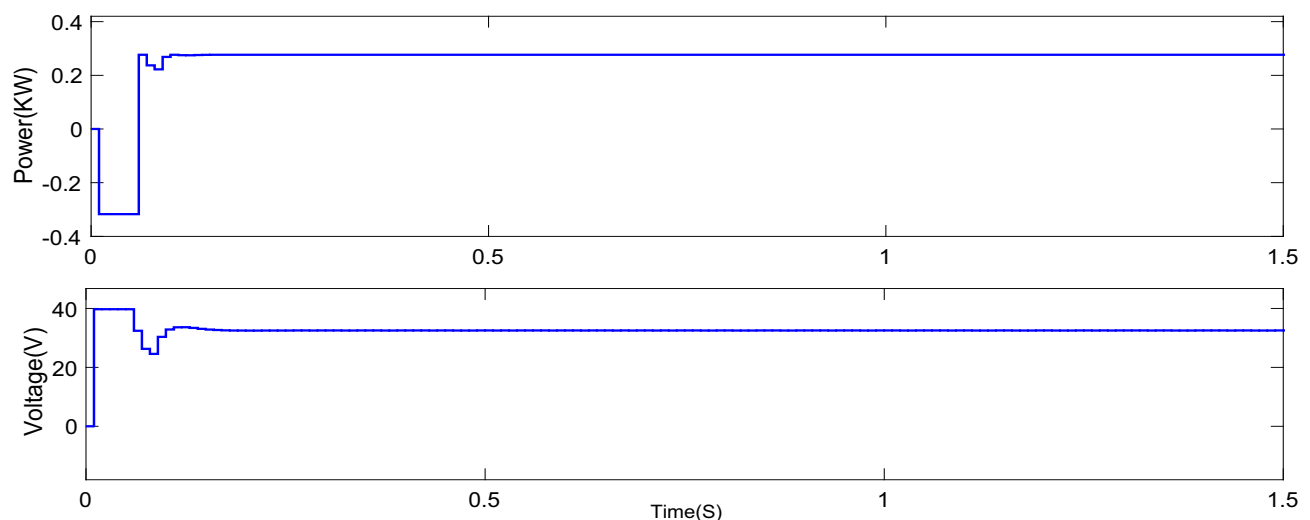

Fig. 7. Offline MPPT $\left(1000 \mathrm{w} / \mathrm{m}^{2} 50^{\circ} \mathrm{C}\right)$
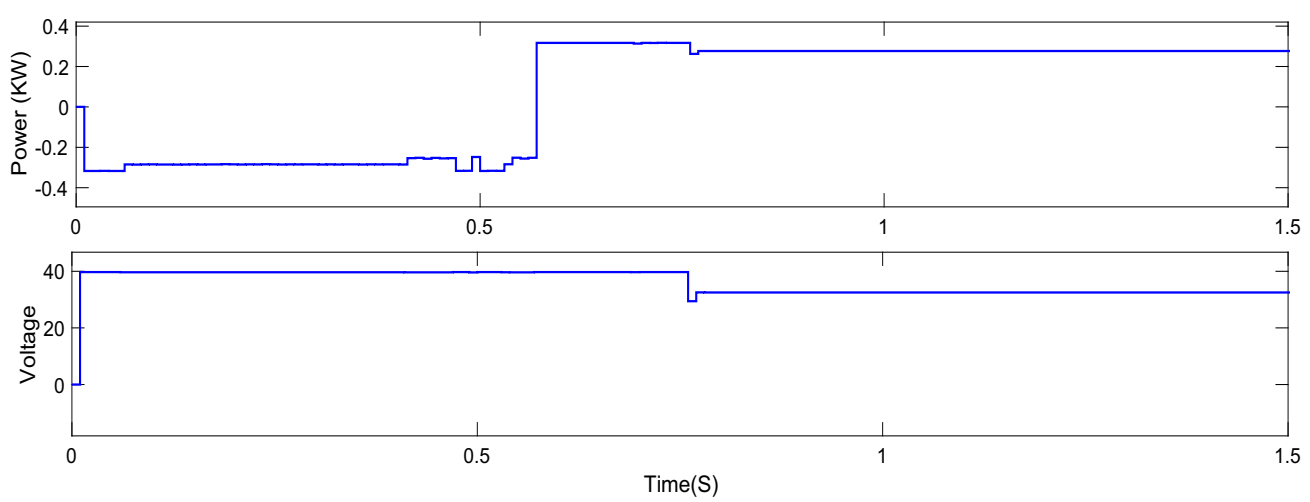

Fig.8. Incremental conductance $\left(1000 \mathrm{w} / \mathrm{m}^{2}, 50^{\circ} \mathrm{C}\right)$

The performance of the offline method is compared to the performance of the system using incremental conductance. In figure 7 , the PV system is using the offline maximum power point tracking while in figure 8 , the PV system is using incremental conductance maximum power point tracking technique. The time taken to reach maximum power by the PV system using the proposed offline method is about $100 \mathrm{~ms}$ while the time taken to reach maximum power using incremental conductance is about $700 \mathrm{~ms}$.

The system can be de-loaded by storing a percentage of the maximum power voltage in the lookup table as the reference voltage. This implies that if the system is required to operate with a $10 \%$ reserve the maximum power voltage will be multiplied by 0.9 before being stored in the look-up table. This is because the voltage is approximately directly proportional to the power up to the maximum power point. The system can also be deloaded by operating it higher than the maximum power voltage but it is more difficult to get it to operate at the desired percentage of maximum power because the power drops steeply after the maximum power point.
This method depends on the behaviour of the PV module and as a result, the accuracy of the system is affected by degradation of the PV module. This can be factored into the calculation of the maximum power voltage.

\section{Conclusion}

This paper describes and tests a fast and accurate method for operating PV systems at maximum power or at maximum power with a predetermined reserve. The $V_{\mathrm{OC}}$ and $I_{\mathrm{SC}}$ are first determined using the temperature coefficients of the PV module and the effects of changing irradiance on the PV. Then the maximum power is determined by obtaining the I-V curve. The points of the I-V curve are obtained by numerically solving the diode equation. This maximum power voltage is stored in a lookup table and is the reference voltage for a given irradiance and temperature. The implementation of the offline method shows that the system reaches maximum power quickly and is faster than when incremental conductance is used. This main 
advantage of this method is the speed at which the reference voltage is determined. The method presented in this work will find application in the use of converter connected sources such as PV and grid-scale batteries in providing frequency support and thus will enable more converter connected sources in electrical grids.

\section{References}

1. N. Masood, N. Modi, 'Low Inertia Power Systems: Frequency Response Challenges and a Possible Solution', Australasian Universities Power Engineering Conference (AUPEC), 25-28 September, (2016).

2. Y.K Wu, 'Frequency Stability for an Island Power System: Developing an Intelligent PreventiveCorrective Control Mechanism for an Offshore Location', IEEE Industry Application Magazine, Vol. 23, Issue 2, pp. 74-87. March-April, (2017).

3. J. Morren, J. Pierik, S.W.H. de Haan, 'Inertia Response of Variable Speed Wind Turbine', Electrical Power Systems Research 76. Pp. 980-987, (2006).

4. L. Wu, 'Provision of Power System Frequency Response in the Context of High Wind Penetration', $\mathrm{PhD}$ Thesis, (2014). Retrieved from: http://oleg.lib.strath.ac.uk/R/?func=dbin-jumpfull\&object_id=24376

5. S. S Sami, 'Virtual Energy Storage for Frequency and Voltage Control', Ph.D Thesis, July (2017).
6. S. S Sami, M. Cheng, J. Wu, 'Modelling and Control of multi-type, Grid-scale Energy Storage for Power System Frequency Response', IEEE $8^{\text {th }}$ International Power Electronics and Motion Conference (IPEMC-ECCE Asia), (2016).

7. M. A. Eltawil, Z. Zhao, 'MPPT Techniques for Photovoltaic Applications', Renewable and Sustainable Energy Reviews. Vol 25. Pp. 793-813. September (2013).

8. L. M. Elobaid, A. K. Abdesalam, E. E. Zakzouk, 'Artificial Neural Network Based Maximum Power Point Tracking Technique for PV Systems', IECON 2012- 38th Annual Conference on IEEE Industrial Electronics Society, October 25-28, (2012).

9. A. Hoke, E. Muljadi, 'Real-time Photovoltaic Plant Maximum Power Point Estimation for use in Grid Frequency Stabilization', Controlling and Modelling for Power Electronics (COMPEl), IEEE $16^{\text {th }}$ workshop 12-15 July (2015).

10. J. Nelson, 'The Physics of Solar Cells', London, Imperial College Press, (2003). Pg. 172-173

11. J. Nelson, 'The Physics of Solar Cells', London, Imperial College Press, (2003). Pg. 173

12. J. Nelson, 'The Physics of Solar Cells', London, Imperial College Press, (2003). Pg. 14-15

13. M. G. Villalva, J. R. Gazoli, 'Comprehensive Approach to Modelling and Simulation of Photovoltaic Arrays', IEEE Transactions on Power Electronics, Vol 24, Issue 5. Pp 1198-1208, (2009). 